Pure Appl. Chem., Vol. 73, No. 12, pp. 2005-2016, 2001.

(C) 2001 IUPAC

\title{
Humic matter and contaminants. General aspects and modeling metal ion binding*
}

\author{
Luuk K. Koopal ${ }^{1, \ddagger}$, Willem H. van Riemsdijk ${ }^{2}$, and David G. Kinniburgh ${ }^{3}$ \\ ${ }^{1}$ Laboratory of Physical Chemistry and Colloid Science, Wageningen University, \\ Dreijenplein 6, 6703 HB Wageningen, The Netherlands; '2 Sub-department of Soil \\ Science and Plant Nutrition, Wageningen University, Dreijenplein 10, 6703 HB \\ Wageningen, The Netherlands; ${ }^{3}$ British Geological Survey, Wallingford, Oxon \\ OX10 8BB, UK
}

\begin{abstract}
Humic substances are soil and fresh-water components that play an important role in the binding and transport of both organic and inorganic contaminants. Transport of the contaminants due to ground- and fresh-water dynamics is directly related to the risks associated with contaminations. The mobility of soluble humic substances is related to their interaction with soil mineral particles. Some key references for the binding of organic and inorganic contaminants and for the binding of humics to mineral particles are presented. Humic substances also play a role in the analysis of the contaminants in natural waters and with remediation of water or soil polluted with pesticides, heavy metal ions, and radionuclides. These aspects are illustrated with some examples. The problems that are encountered with the modeling of the binding of contaminants to humics and of heavy metal ions in particular are illustrated by considering the nonideal competitive adsorption model (NICA) extended with electrostatic interactions. The NICA-Donnan model gives quite good results for the description of metal ion binding, as is illustrated for metal ion binding to purified peat humic acid (PPHA). Finally, some remarks are made with respect to the use of the NICA-Donnan model in general purpose speciation programs and of simplified versions of the model for predictions under restricted environmental conditions.
\end{abstract}

\section{INTRODUCTION}

Humic substances are formed in both terrestrial and aquatic systems. They can be insoluble components that are parts of soil and/or sediment, or be dissolved in ground- or surface water. The soluble humics can also be bound to the other soil/sediment components. The humic matter composition of ecosystems is mainly controlled by a net balance of formation, degradation, and transfer [1-5]. The diagram in Fig. 1 shows the occurrence and flow paths of dissolved humic substances in the natural environment.

Owing to the widespread presence of humics, humic matter plays an important role in binding, transport, analysis, and remediation of pollutants in natural environments. In the first part of the paper, a brief overview will be given of humics and contaminant binding, and some references will be provided on the role of humics in monitoring pollutants and in water and soil or sediment remediation. Modeling of contaminant binding to humics and metal ion binding, in particular, will be discussed in

\footnotetext{
*An issue of reviews and research papers based on presentations made at the IUPAC/ICSU Workshop on Electrochemistry and Interfacial Chemistry in Environmental Clean-up and Green Chemical Processes, Coimbra, Portugal, 6-7 April, 2001.

${ }^{\ddagger}$ Corresponding author: E-mail: koopal@ fenk.wag-ur.nl
} 


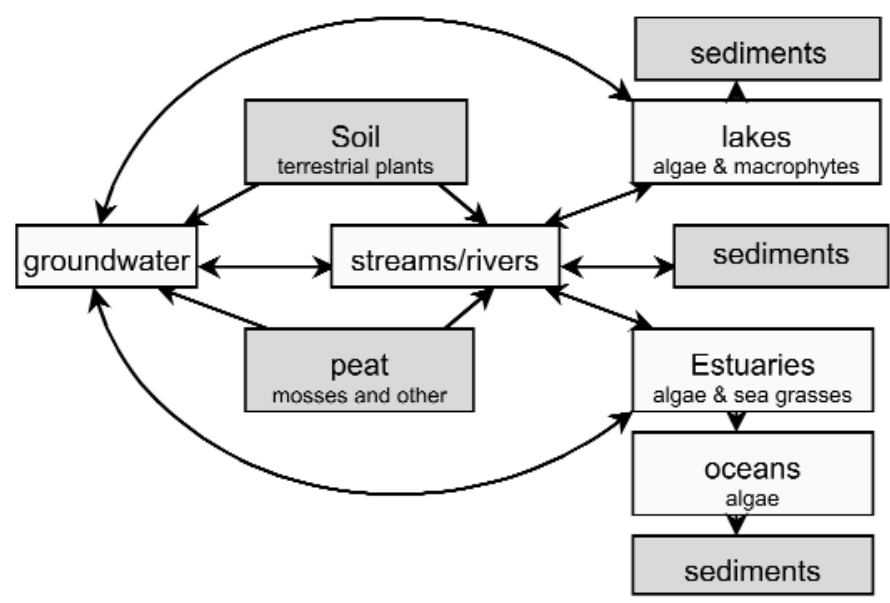

Fig. 1 Diagram of the occurrence and possible environmental flow paths of humic substances.

detail in the second part of the paper. The purpose of this part of the paper is to illustrate that physical insight and common sense are required to obtain a good grip on contaminant binding. Only after systematic studies can predictions be made that are relevant to risk assessment.

\section{HUMIC MATTER AND CONTAMINANTS}

\section{Binding of contaminants and risk assessment}

In the natural environment, humic substances play an important role in the binding of both organic [6-13] and inorganic contaminants [14-20]. Binding of contaminants to humic matter can have a large impact on both the free and the total contaminant concentration in surface waters, soil solutions, and groundwater [5]. The free contaminant concentration is of relevance with respect to bioavailability and toxicity. The contaminant solubility and mobility in natural waters can either be reduced by binding to soil humic matter or be increased by binding to dissolved humic matter. For example, hydrophobic herbicides or pesticides, such as atrazine or tefluthrin, may be captured in hydrophobic cavities of humic substances [7]. As soil humic material is, in general, more hydrophobic than fresh-water humic material, accumulation of hydrophobic pollutants in the soil matrix occurs [6], and this leads to a reduced contaminant solubility.

Transport of the contaminants due to groundwater and fresh-water dynamics is an important factor in the risks associated with contaminations. Transport of contaminants that bind strongly to the mobile natural organic matter may be enhanced in the environment; this phenomenon is known as colloid facilitated transport. However, the mobility of soluble humic substances is also related to the interaction of this humic matter with soil mineral particles [21-34]. Soil contaminants bound to nondissolvable organic matter, to settled particles, or to soluble organic material that is bound to soil mineral particles, all belong to the immobile fraction.

The important role of humic substances with respect to risk assessment of contaminants has led to many binding studies, of which the above mentioned are only examples. A detailed discussion of metal ion binding to humics will be given in the last part of the paper. 


\section{Analysis of contaminants in natural waters}

Apart from the role that humic substances play in the risk assessment of contaminants, they may also play a role with the analysis of the contaminants in natural waters. For example, the presence of dissolved humic material complicates the voltametric determination of metal ion concentrations in natural waters. Not only the diffusion of the metal ions to the mercury surface is important, but also that of the soluble metal ion humic matter complexes. Moreover, the stability and lability of the humic matter metal ion complexes has to be taken into account [35-37].

\section{Humic matter and remediation}

In remediation praxis, the presence of humic matter is important in, for instance, the production of drinking water from surface waters. Rest concentrations of polar pesticides in surface waters are often removed by adsorption to granular activated carbon [38]. The performance of the activated carbon to remove the pesticide depends not only on the properties and concentration of the pesticide molecules, but also on the properties and concentration of dissolved natural organic matter. The concentration of dissolved humics is typically 1000 times higher than the pesticide concentration, so a well-designed experimental set-up is required to obtain an economically feasible process. To avoid expensive largescale test experiments, the results of small-scale laboratory experiments are often used to predict the behavior for full-scale columns [39,40]. Some problems encountered with this approach have been discussed by Heijmans et al. [41]. Najm et al. [42] have addressed the problem that natural organic matter is in fact a multicomponent mixture that competes with the pesticide molecules for the adsorption sites on the carbon surface.

Remediation of water polluted with metal ions or radionuclides is often thwarted because the ions have to be released from metal-humic matter complexes. Examples of studies on water remediation are that of Chiarizia et al. [43], who describe the removal of low concentrations of inorganic contaminants from groundwater using liquid membranes, of Barney et al. [44], who discuss plutonium removal from low-level process wastewater by adsorption, and of Tucker et al. [45], who remove chromate by ultrafiltration.

A general discussion on remediation of contaminated soils has been given by Adriano et al. [46]. Many case studies have been presented at the Contaminated Soil conferences. Removal of heavy metal ions from contaminated soil has been done by, for instance, leaching with solutions of chelating agents [47,48] electrokinetic or electrodialytic techniques [49-51], flotation [52], bacteria in a sludge reactor [53], and by phytoremediation with metal-resistant plants [54].

\section{MODELING METAL ION BINDING TO HUMICS}

\section{General aspects}

As indicated above, metal ion binding to humic matter is of importance since it can have a large impact on the metal ion mobility and free-metal ion concentration in surface waters, soil solutions, and groundwater. There has been a long history of attempts to model metal ion binding to humic substances [5,55]. This type of modeling addresses the speciation of metal ions in the natural environment and is directly related to risk assessment. While the earlier models were quite successful in describing individual data sets, their scope in terms of $\mathrm{pH}$ range, competing metal ions, and ionic strength was often very limited and did not match the range of conditions found in natural waters. The metal binding "constants" were mostly conditional in the sense that they depended on $\mathrm{pH}$, ionic strength, and the presence of other metal ions. Ideally, the binding constants should be a property of the humic substance alone and should not vary with solution chemistry. If binding models are to be used in general purpose chemical speciation programs, as we hope, then they must address these basic issues. The ability to account for proton-metal and metal-metal competition provides a challenging test for such models. 
In the last decade, models that attempt to address these issues have been developed [56-62]. These models show considerable complexity and contain a large number of parameters. We believe that this is unavoidable and reflects the underlying complexity of the system. At the root of this complexity is: (1) the extreme binding site heterogeneity, (2) the variable stoichiometry of the binding reactions, and (3) the presence of electrostatic interactions.

The paper focuses on the nonideal competitive adsorption model (NICA) [58,62], which has been applied to metal ion binding to humics with considerable success. The NICA model addresses heterogeneity, stoichiometry, and electrostatics, yet, its derivation is fairly simple.

\section{NICA model}

As a starting point for the derivation of the NICA model, it was postulated [58] that an equation like the Hill equation could be used to describe the binding of species $i$ on a homogeneous substrate. The Hill equation for local $(L)$ binding of species $i$ on a group of binding sites with equal affinity can be expressed as:

$$
\theta_{i, L}=\frac{\left(K_{i} c_{i}\right)^{n_{i}}}{1+\left(K_{i} c_{i}\right)^{n_{i}}}
$$

where $\theta_{i, L}$ is the fraction of the reference sites occupied by species $i, K_{i}$ is the intrinsic affinity of species $i$ for the reference sites, and $c_{i}$ is the concentration (or activity) of $i$ in solution. In the Hill equation, the exponent $n_{i}$ represents the stoichiometry (cooperativity) of the binding reaction. This means that each reference site becomes occupied with $n_{i}$ molecules of $i$. For the calculation of the bound amount, $Q_{i}$, also the density of reference sites, $Q_{\max }$, is required:

$$
Q_{i}=n_{i} \theta_{i, L} Q_{\max }
$$

The Hill equation (eq. 1) can be easily generalized to the competitive binding of species $i(i=1, \ldots ., j)$ on a group of equal energy sites, $L$ :

$$
\theta_{i, L}=\frac{\left(K_{i} c_{i}\right)^{n_{i}}}{1+\sum_{i}\left(K_{i} c_{i}\right)^{n_{i}}}
$$

Hence, for each component $i$, the coverage of the reference sites is characterized by two parameters, the intrinsic affinity for the reference site, $K_{i}$ and the stoichiometry factor, $n_{i}$. Equation 3 can also be written as:

$$
\theta_{i, L}=\frac{\left(K_{i} c_{i}\right)^{n_{i}}}{\sum_{i}\left(K_{i} c_{i}\right)^{n_{i}}} \cdot \frac{\sum_{i}\left(K_{i} c_{i}\right)^{n_{i}}}{1+\sum_{i}\left(K_{i} c_{i}\right)^{n_{i}}}
$$

where the first quotient at the right-hand side is the fraction of the covered sites that is occupied with $i$ and the second quotient indicates the total number of reference sites bound to an ion. The structure of this equation is also illustrative in relation to the NICA equation to be given below. For a homogeneous substrate, eqs. 3 or 4 gives the binding of species $i$ in the competitive situation. The covered sites will be occupied with $n_{i}$ molecules of $i$, and the adsorbed amount of $i$ is given by eq. 2 , this means that the binding maximum is different for the different components.

The extension of eq. 4 to the overall binding of species $i$ in the competitive situation on a heterogeneous substrate follows by using eq. 4 as a local isotherm in the integral binding equation for heterogeneous site binding [55]. In order to arrive at a convenient analytical solution of the integral binding equation, the equation used for the site heterogeneity is a so-called "Sips distribution" $[63,64]$. This distribution is assumed to be generic, i.e., it is applied under the assumption of a full correlation between the affinity distributions for the different ions. This means that the affinity distributions for the proton and the various metal ions have the same shape, but they are shifted from each other on the 
intrinsic affinity axis. The solution of the thus obtained integral binding equation is the basic NICA equation for the overall binding of species $i$ in the competitive situation [58]:

$$
\theta_{i, t}=\frac{\left(\tilde{K}_{i} c_{i}\right)^{n_{i}}}{\sum_{i}\left(\tilde{K}_{i} c_{i}\right)^{n_{i}}} \cdot \frac{\left\{\sum_{i}\left(\tilde{K}_{i} c_{i}\right)^{n_{i}}\right\}^{p}}{1+\left\{\sum_{i}\left(\tilde{K}_{i} c_{i}\right)^{n_{i}}\right\}^{p}}
$$

where $\theta_{i, t}$ is the fraction of all of the sites occupied by species $i, \tilde{K}_{i}$ is the median value of the affinity distribution for species $i$, and $p$ is the width of the affinity distribution. We stress again that the shape of the distribution is generic (only one $p$ value) and that the position of the distribution on the affinity axis (given by $\tilde{K}_{i}$ ) is specific for component $i$. The meaning of the two quotients on the right-hand side of eq. 5 is the same as in eq. 4.

The total bound amount of component $i, Q_{i, t}$, is now given by:

$$
Q_{i, t}=\theta_{i, t} n_{i} Q_{\max , t}
$$

where $Q_{\text {max }, t}$ is the overall density of the reference sites. Equation 6 reflects again that $n_{i}$ incorporates the stoichiometry, that is to say, on each reference site, $n_{i}$ molecules of $i$ are bound.

In order to access $Q_{\mathrm{max}, t}$ in practice, one has to select a particular component and determine its binding capacity. Most likely, the proton will be used to determine the total proton binding capacity, $Q_{\max , H}$, because this ion can be studied without metal ion competition. Moreover, proton-binding data allow us to extract the site heterogeneity $[65,66]$. The bound amount of component $i$ should now be scaled by $n_{i} / n_{H}$ rather than by $n_{i}$ alone:

$$
Q_{i, t}=\theta_{i, t}\left(n_{i} / n_{H}\right) Q_{\max , H}
$$

Substituting eq. 5 for $\theta_{i, t}$ into eq. 7 defines the basic NICA model in terms of bound amount as a function of the concentrations of the species present.

It should be noticed again that the stoichiometry $n_{i}$ and the adsorption maximum $\left(n_{i} / n_{H}\right) Q_{\max , H}$ are both component-specific. The adsorption maximum will only be the same for all ions if all of the Hill exponents $n_{i}$ (including $n_{H}$ ) are the same. A difference in $n_{i}$ automatically leads to an ion-specific adsorption maximum. For instance, when $n_{i} / n_{H}<1$, the maximum binding that species $i$ can attain is less than the total site density as defined by the protons. This reflects a degree of multidentism for species $i$.

\section{Electrostatic interactions}

Electrostatic interactions can be incorporated in the NICA model through introduction of the electrostatic affinity that ion $i$ experiences on top of the intrinsic affinity. Due to the electrostatic affinity, the solution concentration of ion $i$ in the immediate vicinity of the binding sites, $c_{s, i}$, differs from its bulk concentration by a Boltzmann factor that includes the electrostatic potential at the sites, [66]:

$$
c_{s, i}=c_{i} \exp \left(-z_{i} e \psi_{s} / k T\right)
$$

In eq. $8 z_{i}$ is the valence of the ion (sign included), $e$ is the elementary charge, $k$ the Boltzmann constant, and $T$ is the absolute temperature. Under the assumption of random heterogeneity and neglecting discrete charge effects, the electrostatic potential $\psi_{s}$ can be considered as a generic property independent of the site heterogeneity. The assumption that $\psi_{s}$ is a generic potential also implies that the polydispersity of the humic particles is neglected. Replacing $c_{i}$ in eq. 5 by $c_{s, i}$ gives the NICA equation that includes electrostatic interactions.

In order to be able to calculate the electrostatic potential $\psi_{s}$ from the (variable) charge of the organic colloid (the humic acid molecules), an electrical double layer model [68] is required, and this involves further simplifying assumptions related to the type of particles and their size, shape, and conformation. In general, two types of models are used, one is based on the assumption that the organic 
colloid is impenetrable for ions (surface charge models) [61,65,68-72], the other considers the colloid as a gel phase in which all charges of the organic matter are compensated within the gel phase (Donnan models) [59-62,68,73-79]. Mostly, it is assumed that the humic particles are spherical.

In surface charge models [61,65,68-72], the charge of the particles is assumed to reside as a smeared-out charge density at the surface of (mostly) spherical particles. The electrostatic potential at the sites is, in this case, equivalent to the surface potential and can be calculated from the surface charge density using a double layer model for hard spheres [68].

In the Donnan models [59-62,68,73-79], the charge due to the dissociation of the functional groups of a particle is smeared out over the volume of the (mostly) spherical particle, and a volume charge density is obtained. The volume charge density is now converted into the Donnan potential, a potential that is assumed to be the same everywhere inside the volume of the particle and zero outside the particle boundary [68].

For both models, in principle, an estimate of the size of the particles as a function of $\mathrm{pH}$ and ionic strength is required in order to be able to calculate the specific surface area or the specific volume. In practice, the influence of either or both $\mathrm{pH}$ and ionic strength is not always considered. For instance, De Wit et al. [65,71] have used the surface charge model with a particle radius independent of $\mathrm{pH}$ and ionic strength, whereas in Benedetti et al. [59] and several more recent papers [66-68] the Donnan model has been used with a Donnan volume that only depends on the ionic strength. The reasons for using the latter model are dictated by convenience rather than by principle. Avena et al. [68] have shown that the approach of Benedetti et al. [59] gives good results, but that the surface charge model, with an experimentally obtained particle radius that is $\mathrm{pH}$ - and salt concentration-dependent, is physically speaking more realistic.

\section{NICA and thermodynamic consistency}

In the original NICA paper [58], a generalized interpretation was given of eq. 1 and of $n_{i}$. It was assumed that eq. 1 could represent either: (i) the Hill equation, (ii) the extended Henderson-Hasselbalch equation (in which $n_{i}$ accounts for lateral interactions), or (iii) the Langmuir-Freundlich equation (with $n_{i}$ expressing a site heterogeneity). Hence, $n_{i}$ was thought to reflect an overall non-ideality. However, with this generalized interpretation of eq. 1 , the calculation of the adsorbed amount remains obscure. In [58] this problem was insufficiently recognized, and no mentioning was made of an equation for the bound amount. If it is assumed that $n_{i}$ is component-specific with different values for different components, the only thermodynamically consistent interpretation of eqs. 3 and 5 is that $n_{i}$ is a stoichiometry factor and that the adsorbed amount should be given by eqs. 6 or 7 . As a consequence, eqs. 1 and 3 represent the mono- and multicomponent Hill equation with the bound amount given by eq. 2 . Kinniburgh et al. [62] have addressed this problem, but the consequences for the physical interpretation of eq. 1 were not discussed.

If it is assumed that $n_{i}$ is a generic (instead of a specific) non-ideality parameter that is the same for all components, then the NICA equation with eq. 7 for the adsorbed amount is, of course, also thermodynamically consistent. In this specific case, eq. 1 can be seen as an equation that incorporates a generic non-ideality related to heterogeneity and/or lateral interactions.

The ratio $n_{i} / n_{H}$ in eq. 7 has been neglected in [58-60] when the NICA model was applied to experimental data. In the case that $n_{i}$ and $n_{H}$ are (substantially) different (e.g., for $\mathrm{H} / \mathrm{Cu}$ ), this results in a description of the binding that is thermodynamically inconsistent and, therefore, incorrect.

In [62], the NICA model was indicated as nonideal consistent competitive adsorption (NICCA) model. However, two names for the same model easily leads to confusion. The name NICA is to be preferred, the equations presented in [58] are correct, the shortcoming of [58] is that eq. 6 or 7 is not specified. 


\section{Experimental results and model calculations}

The NICA-Donnan model has been shown [62] to give quite good results for the description of an extensive data set for the binding of protons and of the metal ions $\left(\mathrm{Ca}^{2+}, \mathrm{Cd}^{2+}, \mathrm{Cu}^{2+}, \mathrm{Pb}^{2+}\right.$, and $\left.\mathrm{Al}^{3+}\right)$ to a purified peat humic acid (PPHA) at various $\mathrm{pH}$ values. In order to arrive at this quality of fit, bimodal affinity distributions (accounting for carboxylic and phenolic type groups) are required. For the total binding of component $i$ this leads to a summation of two NICA equations in combination with one Donnan model for the calculation of the electrical potential. Reasonable predictions are also obtained of the $\mathrm{H}^{+} / \mathrm{M}^{\mathrm{Z}}$ exchange ratios which for $\mathrm{Cu}^{2+}, \mathrm{Pb}^{2+}$, and $\mathrm{Al}^{3+}$ are greater than one. This agreement is highly desirable from a theoretical point of view and is of benefit in predicting $\mathrm{pH}$ changes in systems with high metal ion loading. Finally, the model gives reasonable predictions for the competition calcium-cadmium, calcium-copper, and lead-aluminium.

Some results are presented in Figs. 2 and 3 that show that the fit of the NICA-Donnan model to the $\mathrm{Ca}^{2+}$ and $\mathrm{Cd}^{2+}$ binding data over a wide range of $\mathrm{pH}$ and $\mathrm{Ca}^{2+}$ or $\mathrm{Cd}^{2+}$ concentrations is excellent.

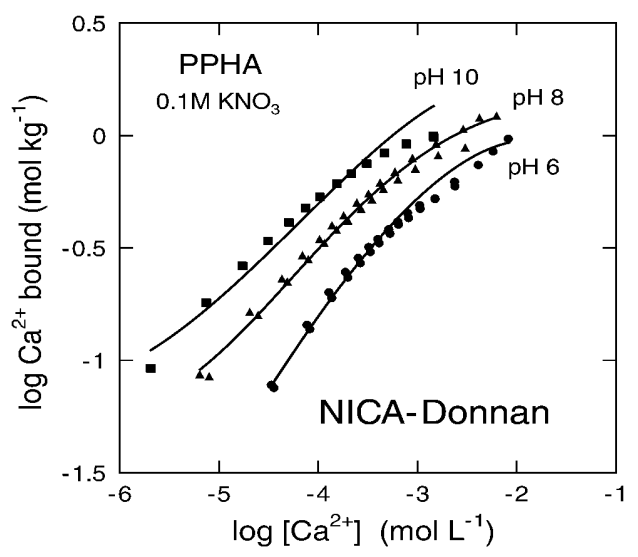

Fig. 2 Calcium binding by PPHA at $\mathrm{pH} \mathrm{6,8}$, and 10 and $0.1 \mathrm{M} \mathrm{KNO}_{3}$. Points are observations, and lines are calculated from the NICA-Donnan model [62].

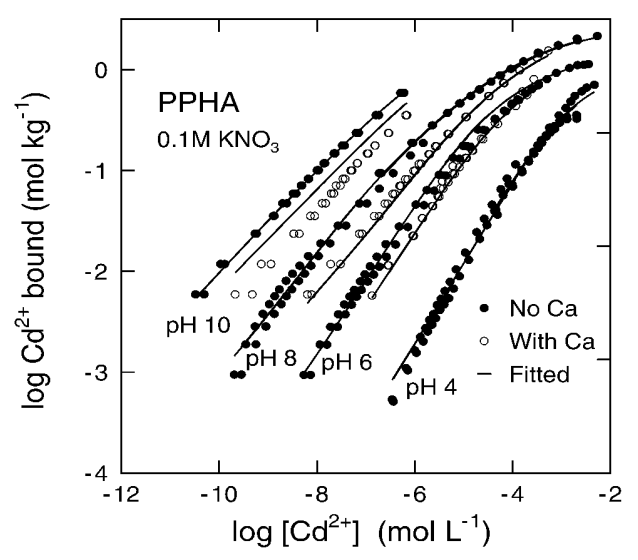

Fig. 3 Cadmium binding by PPHA in the absence (filled points) and presence (open points) of $\mathrm{Ca}^{2+}$ (molar $\log$ $\left[\mathrm{Ca}^{2+}\right]$ mostly from -3.5 to -3.0$)$ at $\mathrm{pH} 4,6,8$, and 10 and $0.1 \mathrm{M} \mathrm{KNO}_{3}$. Points are observations, and lines are calculated from the NICA-Donnan model calibrated using only single-metal $\mathrm{Cd}^{2+}$ and $\mathrm{Ca}^{2+}$ data [62]. 
Figure 3 shows too that the model is also able to predict the behavior in mixed $\mathrm{Ca}^{2+}-\mathrm{Cd}^{2+}$ systems reasonably well (but not perfect). For further results on PPHA, [62] should be consulted.

Recently, the metal ion binding data for PPHA have been extended to the effect of aluminium competition on lead and cadmium binding at various values of the ionic strength [76]. Good results were obtained provided the NICA-Donnan parameters for $\mathrm{Al}$ and $\mathrm{Pb}$ were redetermined. For $\mathrm{H}$ and $\mathrm{Cd}$, the parameters as given in [62] could be used.

After the description of the PPHA data set by the NICA-Donnan model, the model has been applied successfully to the description of proton and metal ion binding data to various other humic and fulvic acids [75-79]. In their work, Christl et al. [78,79] have shown that it was possible to reduce the number of fitting parameters if results from size exclusion chromatography and solid-state C-13 NMR spectroscopy were used to estimate two of the parameters. Moreover, this procedure resulted in a more consistent parameter set than by fitting alone.

\section{Discussion of the NICA model}

The above derivation leads in a straightforward manner to the NICA model, a thermodynamically consistent competitive binding model for heterogeneous systems and a component-specific binding stoichiometry. Moreover, the NICA model is easily adapted to include electrostatic interactions. In principle, the model can be used for competitive binding of various kinds of solutes on charged or uncharged heterogeneous substrates.

Although the NICA model is quite sophisticated, it should be realized that metal ion binding to humics is a very complex process. Most assumptions that have been made in the derivation of the NICA-Donnan model are still severe simplifications of the complex reality. Hence, by fitting the NICADonnan model to a data set, the model should be regarded as semi-empirical. When (part of) the assumptions that are made to arrive at the model are violated, the physical meaning of the resulting parameter values becomes somewhat obscure. For instance, in the derivation of the model, the values of $n_{i}$ and $p$ are related to respectively the ion-specific stoichiometry and the generic heterogeneity. However, due to the fitting procedure, the values of $n_{i}$ and $p$ will be affected by complexities (non-ideality contributions) that were not included in the model.

The fact that eq. 1 can be interpreted in different ways [58], immediately suggests that $n_{i}$ might be rather sensitive to non-ideality contributions not specified in the derivation of the model. Yet, substantial differences in $n_{i}$ for the different components will be a strong indication for differences in stoichiometry of the binding reaction.

When the observed values of $n_{i}$ for the different components are equal (or very similar), the physical meaning of $n_{i}$ may also be related to the heterogeneity of the humic acid. This stems from the fact that for $n_{i}=n_{H}(i=1,2, \ldots)$ eqs. 1 and 3 can also be interpreted as Langmuir-Freundlich equations in which $n_{i}$ represents a first (generic) heterogeneity distribution. By combining eq. 3 with a second (also generic) heterogeneity distribution to obtain the overall isotherm, the NICA equation is obtained, and $p$ serves as a subsequent heterogeneity parameter. As long as $n_{i}=n_{H}(i=1,2, \ldots)$ this interpretation is not violating the thermodynamic consistency rules.

A somewhat similar interpretation based on ideal local adsorption behavior (competitive Langmuir equation) and a complex heterogeneity has been suggested by Rusch et al. [80]. These authors have shown for a two-component case that the NICA equation with $n_{i}=n_{H}$ may be interpreted as a description of competitive binding to a heterogeneous sorbent in which the two species experience a complex heterogeneity composed of two distributions that are partially correlated.

With the interpretation of the calculated electrostatic potentials, a similar caution applies. The calculated potentials are only a first-order approximation of the true electrostatic potentials near the binding sites, see also [68].

Although it should be realized that the NICA-Donnan model if applied to humic or fulvic acids should be regarded as semi-empirical, the physical insights incorporated in the model are still very 
important for a successful application of the model. Due to the high degree of sophistication of the NICA model extended with electrostatic interactions, the parameter values that are obtained by fitting the model to a data set are independent of the environmental conditions ( $\mathrm{pH}$, ionic strength). This makes the model well suited for predictions inside and outside the range of conditions where the parameters were fitted and for applications within general purpose chemical speciation programs.

Some clear indications that the NICA-Donnan model, supplied with model constants that were obtained for a specific humic acid, can be applied successfully to predict field situations have been presented in [81]. To investigate the range in which the NICA-Donnan model parameters can vary for different humic substances, Milne et al. [77] have analyzed a large series of proton binding data, and Christl et al. have studied proton [78] and metal binding [79] to a series of humics. The results show that there is a fair degree of similarity between the model constants obtained for different humics, especially when humic and fulvic acids are considered as two separate classes. This type of result is in agreement with earlier studies of Tipping [56,57] regarding his models V and VI for proton and metal ion binding to humics.

When the conditions under which the metal ion binding takes place do not change, it is often possible to simplify the NICA model and to indicate how the parameters of the simplified model will depend on the environmental conditions. Temminghoff et al. applied such a simplified version of the NICA model to cadmium [82] and copper [83] binding in order to be able to describe the metal ion mobility in sandy soils at various environmental conditions. On the basis of the laboratory results, Temminghoff et al. [84] predicted also what would happen with the dynamic copper balance of contaminated sandy soil upon an increasing soil organic matter content and variations in $\mathrm{pH}$. Plette et al. [85] have used a simplified version of the NICA equation for zinc and cadmium binding to bacteria.

\section{ACKNOWLEDGMENT}

This paper is published with the permission of the Director of the British Geological Survey (NERC).

\section{REFERENCES}

1. F. J. Stevenson Humus Chemistry. Genesis, Composition, Reactions, Wiley Interscience, New York (1982).

2. M. H. B. Hayes, P. MacCarthy, R. L. Malcolm, R. S. Swift. Humic Substances II: In Search of Structure, Wiley Interscience, New York (1989).

3. M. Schnitzer, S. U. Khan. Humic Substances in the Environment, Marcel Dekker, New York (1972)

4. G. R. Aiken, D. M. McKnight, R. L. Wershaw, P. MacCarthy. Humic Substances in Soil, Sediment, and Water, Wiley Interscience, New York (1985).

5. J. Buffle. Complexation Reactions in Aquatic Systems, Ellis Horwood, Chichester, (1988).

6. E. M. Murphy, J. M. Zachara, S. C. Smith, J. L. Philips, T. W. Wietsma. Environ. Sci. Technol. 28, 1291 (1994).

7. J. L. Zhou, S. J. Rowland, J. Braven, R. F. C. Mantoura, B. J. Harland. Int. J. Env. Anal. Chem. 58, 275 (1995).

8. C. T. Chiou, L. J. Peters, V. H. Freed. Science 206, 831 (1979).

9. R. P. Schwarzenbach and J. Westall. Environ. Sci. Technol. 15, 1360 (1981).

10. J. J. Pignatello. Environ. Toxicol. Chem., 9, 1107 (1990).

11. J. J. Pignatello and B. Xing, Environ. Sci. Technol. 30, 1 (1996).

12. W. J. Weber Jr. and W. Huang. Environ. Sci. Technol. 30, 881 (1996).

13. W. J. Weber, W. Huang, E. J. LeBoeuf. Colloids Surfaces A 151, 167 (1999).

14. D. M. McKnight, R. L. Wershaw, K. E. Bencala, G. W. Zellweger, G. L Feder. Sci. Total Environ. 117/118, 485 (1992). 
15. R. M. Town and H. K. J. Powell. Anal. Chim. Acta 279, 221 (1993).

16. J. Buffle. "Natural organic matter and metal-organic interactions in aquatic systems", in Metal Ions in Biological Systems, H. Sigel (Ed.), p. 165, Marcel Dekker, New York (1984).

17. J. H. Ephraim, J. A. Marinsky, S. J. Cramer. Talanta 36, 437 (1989).

18. G. Sposito. CRC Crit. Rev. Environ. Control 16, 193 (1986).

19. E. Tipping, J. R. Griffith, J. Hilton. Croat. Chem. Acta 56, 613 (1983).

20. A. P. W. Vermeer, J. K. McCulloch, W. H. Van Riemsdijk, L. K. Koopal. Environ. Sci. Technol. 33, 3892 (1999).

21. R. L. Parfitt, A. R. Fraser, V. C. Farmer. J. Soil Sci. 28, 289 (1977).

22. J. A. Davis. Geochim. Cosmochim. Acta 46, 2381 (1982).

23. E. Tipping. Geochim. Cosmochim. Acta 33, 81-89 1981).

24. E. Tipping. Geochim. Cosmochim. Acta 45, 191 (1981).

25. E. Tipping, J. R. Griffith, J. Hilton. Croat. Chem. Acta 56, 613 (1983).

26. E. M. Murphy, J. M. Zachara, S. C. Smith, J. L. Philips. Sci. Total Environ. 117/118, 413 (1992).

27. B. Gu, J. Schmitt, Z. Chen, L. Liang, J. F. McCarthy. Environ. Sci. Technol. 28, 38 (1994).

28. B. Gu, J. Schmitt, Z. Chen, L. Liang, J. F. McCarthy. Geochim. Cosmochim. Acta 59, 219 (1995).

29. J. L. Zhou, S. J. Rowland, R. Fauzi, R. F. C. Mantoura, J. Braven. Water Res. 28, 571 (1994).

30. A. W. P. Vermeer, W. H. van Riemsdijk, L. K. Koopal. Langmuir 14, 2810 (1998).

31. A. W. P. Vermeer and L. K. Koopal. Langmuir 14, 4210 (1998).

32. J. P. Pinheiro, A. M. Mota, M. S. Goncalves, H. P. van Leeuwen. Environ. Sci. Technol. 28, 2112 (1994)

33. M. J. Avena and L. K. Koopal. Environ. Sci. Technol. 32, 2572 (1998).

34. M. J. Avena and L. K. Koopal. Environ. Sci. Technol. 33, 2739 (1999).

35. M. Filella, J. Buffle, H. P. van Leeuwen. Anal. Chim. Acta 232, 209 (1990).

36. H. P. van Leeuwen and J. Buffle. J. Electroanal. Chem. 296, 359 (1990).

37. J. P. Pinheiro, A. M. Mota, H. P. van Leeuwen. Colloids Surfaces A 151, 181 (1999).

38. I. Suffet and M. J. McGuire (Eds.). Activated Carbon Adsorption of Organics from the Aqueous Phase, Ann Arbor Science, Ann Arbor, MI (1980).

39. J. C. Crittenden, P. S. Reddy, D. W. Hand, H. Arora. AWWA Research Foundation, Denver 83, 57 (1991).

40. J. L. Bulloch, D. W. Hand, J. C. Crittenden. Water Environ. Res. 70, 15 (1998).

41. S. G. J. Heijman and R. Hopmam. Colloids Surfaces A 151, 303 (1999).

42. I. N. Najm, V. L. Snoeyink, J. Richard. J. Am. Water Works Assoc. 57 (1991).

43. R. Chiarizia, E. P. Horwitz, K. M. Hodgson. In Environmental Remediation: Removing Organic and Metal Ion Pollutants, G. F. Vandegrift, D. T. Reed, I. R. Tasker (Eds.), ACS Symposium Series 509, 22 (1992).

44. G. S. Barney, K. J. Lueck, J. W. Green. In Environmental Remediation: Removing Organic and Metal Ion Pollutants, G. F. Vandegrift, D. T. Reed, I. R. Tasker (Eds.), ACS Symposium Series 509, 34 (1992).

45. E. E. Tucker, S. D. Christian, J. F. Scamehorn, H. Uchiyama, W. Guo. In Transport and Remediation of Subsurface Contaminants, D. A. Sabatini and R. C. Knox (Eds.), ACS Symposium Series 491, 84 (1992).

46. D. C. Adriano, A. Chlopecka, D. I. Kaplan, H. Clijsters, J Vangronsveld. In Contaminated Soils, R. Prost (Ed.), Les Colloques, INRA, Paris, 85, 465 (1997).

47. R. W. Peters and L. Shem. In Removing Organic and Metal Ion Pollutants, G. F. Vandegrift, D. T. Reed, I. R. Tasker (Eds.), ACS Symposium Series 509, 70 (1992).

48. N. Papassiopi, S. Tambouris, C. Skoufadis, A. Kontopoulus. In Contaminated Soil '98, p. 461, Thomas Telford, London (1998).

49. L. Ottosen, J. B. Jensen, A. Villumsen, S. Laursen, H. K. Hansen, P. Sloth. In Contaminated Soil '95, W. J. van den Brink, R. Bosman, F. Arendt (Eds.), p. 1029, Kluwer, Dordrecht (1995). 
50. L. Ottosen, H. K. Hansen, L. Hansen, B. K. Kliem, G. Bech-Nielsen, B. Pettersen, A. Villumsen. In Contaminated Soil '98, p. 471, Thomas Telford, London (1998).

51. R. Haus and K. Czurda. In Contaminated Soil 2000, p. 1052, Thomas Telford, London (2000).

52. T. Venghaus and J. Werther. In Contaminated Soil '98, p. 479, Thomas Telford, London (1998).

53. L. Diels, M. De Smet, L. Hooyberghs, L. Kinnaer, P. Corbisier, G. Brox. In Contaminated Soil 2000, p. 1043, Thomas Telford, London (2000).

54. A. Leeson and B. C. Alleman. Phytoremediation and Innovative Strategies for Specialized Remedial Applications, Batelle Press, Columbus, OH (1999).

55. W. H. van Riemsdijk and L. K. Koopal. In Environmental Particles, J. Buffle and H. P. van Leeuwen (Eds.), Vol. 1, p. 455, Lewis, London (1992).

56. E. Tipping and M. A. Hurley. Geochim. Cosmochim. Acta 56, 3627 (1992).

57. E. Tipping. Aquatic Geochem. 4, 3 (1998).

58. L. K. Koopal, W. H. van Riemsdijk, J. C. M. de Wit, M. H. Benedetti. J. Colloid Interface Sci. 166, 51 (1994).

59. M. F. Benedetti, C. J. Milne, D. G. Kinniburgh, W. H. van Riemsdijk, L. K. Koopal. Environ. Sci. Technol. 29, 446 (1995).

60. D. G. Kinniburgh, C. J. Milne, M. F. Benedetti, J. P Pinheiro, J. Filius, L. K. Koopal, W. H. van Riemsdijk. Environ. Sci. Technol. 30, 1687 (1996).

61. D. G. Kinniburgh, W. H. van Riemsdijk, L. K. Koopal, M. H. Benedetti. In Adsorption of Metals by Geomedia, E. A Jenne (Ed.), Chap. 23, Academic, San Diego (1998).

62. D. G. Kinniburgh, W. H. van Riemsdijk, L. K. Koopal, M. Borkovec, M. H. Benedetti, M. J. Avena. Colloids Surfaces A 151, 147 (1999).

63. R. Sips. J.Phys. Chem. 16, 490 (1948).

64. R. Sips. J. Phys. Chem. 18, 1024 (1950).

65. J. C. M. de Wit, W. H. van Riemsdijk, M. M. Nederlof, D. G. Kinniburgh, L. K. Koopal. Anal. Chim. Acta 232, 189 (1990).

66. M. M. Nederlof, J. C. M. de Wit, W. H. van Riemsdijk, L. K. Koopal. Environ. Sci. Technol. 27, 846 (1993).

67. T. Healy and L. R. White. Adv. Colloid Interface Sci. 9, 303 (1978).

68. M. J. Avena, L. K. Koopal, W. H. van Riemsdijk. J. Colloid Interface Sci. 217, 37 (1999); M. J. Avena, A. P. W. Vermeer, L. K. Koopal. Colloids Surfaces A 151, 213 (1999).

69. P. Barak and Y. Chen. Soil Sci. 154, 184 (1992).

70. B. M. Bartschat, S. E. Cabanis, F. M. M. Morel. Environ. Sci. Technol. 26, 284 (1992).

71. J. C. M. de Wit, L. K. Koopal, W. H. van Riemsdijk. Environ. Sci. Technol. 27, 2005 (1993).

72. C. J. Milne, D. G. Kinniburgh, J. C. M. de Wit, W. H. van Riemsdijk, L. K. Koopal. Geochim. Cosmochim. Acta 59, 1101 (1995).

73. J. A. Marinsky. In Aquatic Surface Chemistry, W. Stumm (Ed.), Chap. 3, Wiley, New York (1987).

74. M. F. Benedetti, W. H. van Riemsdijk, L. K. Koopal. Environ. Sci. Technol. 30, 1805 (1996).

75. J. P. Pinheiro, A. M. Mota, M. F. Benedetti. Environ. Sci. Technol. 33, 3398 (1999).

76. J. P. Pinheiro, A. M. Mota, M. F. Benedetti. Environ. Sci. Technol. 34, 5137 (2000).

77. C. J. Milne, D. G. Kinniburgh, E. Tipping. Environ. Sci. Technol. 35, 2049 (2001).

78. I. Christl and R. Kretzschmar. Environ. Sci. Technol. 35, 2505 (2001).

79. I. Christl, C. J. Milne, D. G. Kinniburgh, R. Kretzschmar. Environ. Sci. Technol. 35, 2512 (2001).

80. U. Rusch, M. Borkovec, J. Daicac, W. H. van Riemsdijk. J. Colloid Interface Sci. 191, 247 (1997).

81. M. F. Benedetti, W. H. van Riemsdijk, L. K. Koopal, D. G. Kinniburgh, D. C. Gooddy, C. J. Milne. Geochim. Cosmochim. Acta 60, 2503 (1996).

82. E. J. M. Temminghoff, S. E .A. T. M. van der Zee, F. A. M. de Haan Eur. J. Soil Sci. 46, 649 (1995). 
83. E. J. M. Temminghoff, S. E. A. T. M. van der Zee, F. A. M. de Haan Eur. Environ. Sci. Technol. 31, 1109 (1997).

84. S. W. Moolenaar, E. J. M. Temminghoff, F. A. M. de Haan. Environ. Pollution, 103, 117-125 (1998).

85. A. C. C. Plette, M. F. Benedetti, W. H. van Riemsdijk. Environ. Sci. Technol. 30, 1902 (1996). 